\title{
The Relationship of Insulin Response to a Glucose Stimulus over a Wide Range of Glucose Tolerance
}

\author{
P. Zimmet, S. Whitehouse, F. Alford, and D. Chisholm \\ Department of Metabolic Medicine and Epidemiology, Southern Memorial Hospital, and Endocrine Unit, \\ St. Vincent's Hospital, Melbourne, Australia
}

Summary. Oral glucose $(75 \mathrm{~g})$ tolerance tests were performed on 189 urbanized Micronesians with an age range of 15 to 70 years. The subjects were divided into 6 groups on the basis of the $2 \mathrm{~h}$ plasma glucose and the pattern of insulin response examined. Fasting plasma insulin levels were not significantly different over the entire range of glucose tolerance. The $2 \mathrm{~h}$ plasma insulin levels were highest in the group with $2 \mathrm{~h}$ plasma glucose value of $140-199 \mathrm{mg} /$ $100 \mathrm{ml}$. There was a progressive fall in $2 \mathrm{~h}$ plasma insulin with increasing glucose intolerance, so that in the group with a $2 \mathrm{~h}$ plasma glucose $\geqslant 400 \mathrm{mg} /$ $100 \mathrm{ml}$, the $2 \mathrm{~h}$ plasma insulin level was significantly less than that in all the other groups. Obesity was the most important factor influencing both fasting and $2 \mathrm{~h}$ insulin levels and no effect of corresponding plasma glucose level was demonstrated. In maturityonset diabetes, a wide range of insulin responses may be seen and the earlier controversy regarding patterns of insulin response has arisen from equating groups of diabetic subjects with varying degrees of glucose intolerance.

Key words: Glucose tolerance, insulin secretion, maturity onset diabetes, plasma glucose, Micronesians.

Controversy exists as to the "characteristic" plasma insulin pattern in maturity-onset diabetic subjects, and various responses ranging from hypoinsulinaemia to hyperinsulinaemia have been reported [1-4].

An important contribution to the debate came from a study on the American Pima Indians where insulin responses to oral carbohydrate over a wide spectrum of glucose tolerance were measured [4]. Different patterns of insulin response were seen in relation to the degree of glucose intolerance: subjects with mild glucose intolerance showed greater than normal insulin responses, while groups with higher degrees of glucose intolerance showed progressively diminishing insulin responses. Confirmation of these studies in other populations could be of importance.

Recently, a Micronesian population with a high diabetes prevalence $-34.4 \%$ in subjects 15 years and over - has been described [5]. This prevalence is almost identical to that reported in the Pima Indians [6], and the Micronesian population afforded a unique opportunity to study further insulin responses in a group of people over a wide spectrum of glucose tolerance.

\section{Materials and Methods}

The plasma insulin responses to an oral glucose load were evaluated in the 189 Micronesians. A total of 102 females and 87 males, with an age range of 15 to 70 years, were studied. The subjects were not receiving any other medication at the time of testing.

The glucose tolerance of the subjects varied widely from normal to markedly abnormal. The people tested were a randomlyselected sample of the indigenous population of the Central Pacific island of Nauru. They had participated in a diabetes prevalence study, the details of which have been reported previously [5]. At the time of testing, none of the subjects were taking insulin or oral hypo-glycaemic agents and none had previously received insulin. Body mass index (weight $(\mathrm{kg}) /$ height $(\mathrm{m})^{2}$ ) was used as the index of obesity. This has been found to be a reliable index of obesity in Pacific [10] and Caucasian populations [11].

All subjects were on unrestricted diets (the average Nauruan daily diet contains over $350 \mathrm{~g}$ of carbohydrate [7]). Following an overnight fast, the subjects consumed a $75 \mathrm{~g}$ oral glucose load. Venous blood samples were taken fasting and at two hours $(2 \mathrm{~h})$. Plasma glucose levels were measured by a glucose oxidase method as previously reported [5], and insulin determinations were performed by radio-immunoassay using insulin- $\mathrm{I}^{125}$ purified by ionexchange technique [8] and charcoal dextran separation [9]. 

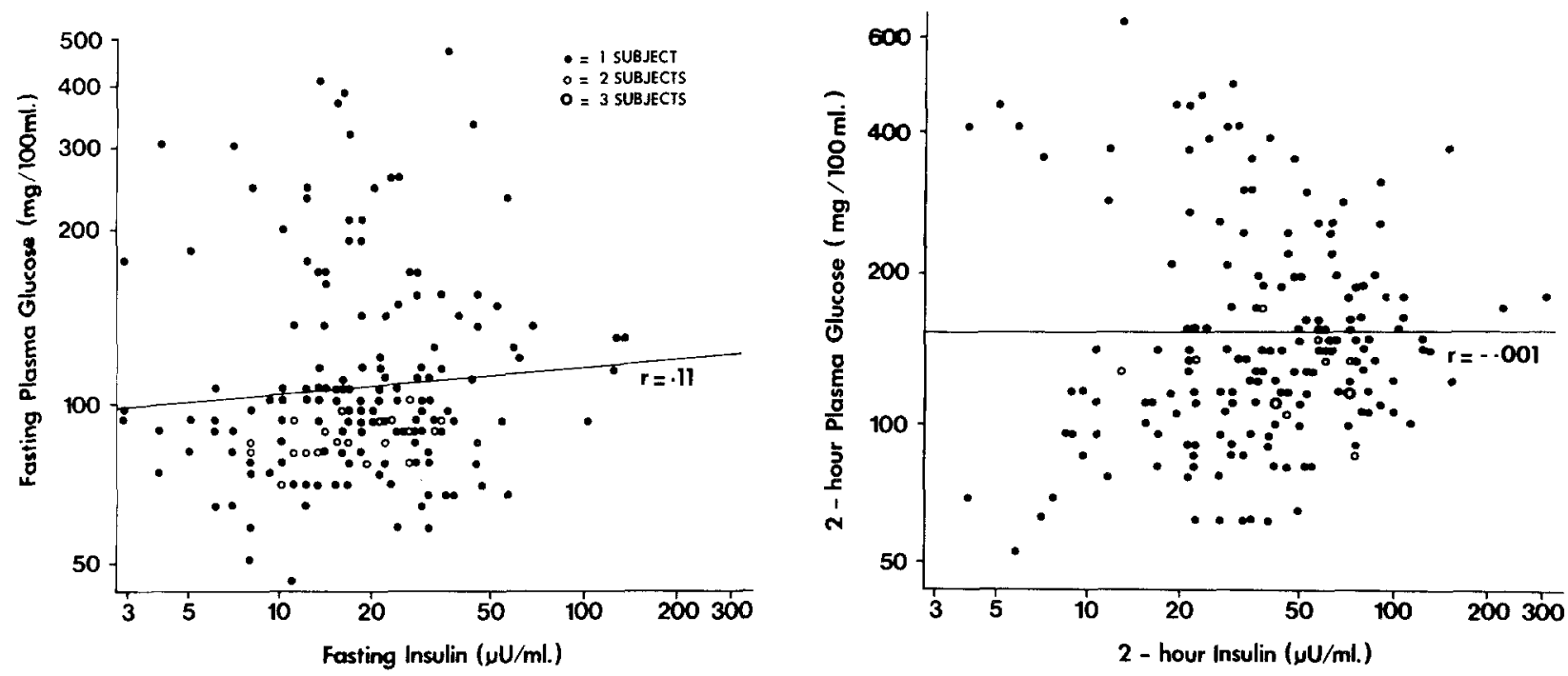

Fig. 1. Relationship between $\log$ plasma glucose and $\log$ plasma insulin concentration both fasting $(n=189, r=0.11, N$. S.) and at 2 hours $(\mathrm{n}=189, \mathrm{r}=-0.001$, N.S. $)$

Table 1. Mean \pm SEM values for body mass index and fasting and $2 \mathrm{~h}$ plasma glucose and insulin values according to $2 \mathrm{~h}$ plasma glucose range

\begin{tabular}{|c|c|c|c|c|c|c|c|}
\hline Group & $\begin{array}{l}2 \mathrm{~h} \\
\text { glucose }\end{array}$ & No. of & Body mass & $\begin{array}{l}\text { Plasma glucose } \\
(\mathrm{mg} / 100 \mathrm{ml})\end{array}$ & & $\begin{array}{l}\text { Plasma insulin } \\
(\mu \mathrm{U} / \mathrm{ml})\end{array}$ & \\
\hline & $\begin{array}{l}\text { range } \\
(\mathrm{mg} / 100 \mathrm{ml})\end{array}$ & subjects & $\begin{array}{l}\text { index } \\
\left(\mathrm{W} / \mathrm{H}^{2}\right)\end{array}$ & Fasting & $2 \mathrm{~h}$ & Fasting & $2 \mathrm{~h}$ \\
\hline 1 & $0-99$ & 36 & $32.4 \pm 1.3$ & $84 \pm 4$ & $83 \pm 2$ & $21 \pm 3$ & $32 \pm 4$ \\
\hline 2 & $100-139$ & 63 & $31.9 \pm 0.8$ & $90 \pm 2$ & $121 \pm 1$ & $22 \pm 2$ & $51 \pm 4^{b}$ \\
\hline 3 & $140-199$ & 46 & $33.8 \pm 1.3$ & $109 \pm 4$ & $162 \pm 2$ & $32 \pm 7$ & $76 \pm 9^{c}$ \\
\hline 4 & $200-279$ & 17 & $33.0 \pm 1.4$ & $161 \pm 19$ & $232 \pm 6$ & $24 \pm 3$ & $54 \pm 5^{c}$ \\
\hline 5 & $280-399$ & 14 & $32.6 \pm 1.4$ & $210 \pm 16$ & $335 \pm 10$ & $26 \pm 9$ & $48 \pm 12$ \\
\hline 6 & $\geqslant 400$ & 13 & $31.7 \pm 1.7$ & $299 \pm 24$ & $471 \pm 21$ & $16 \pm 3$ & $19 \pm 3^{a}$ \\
\hline
\end{tabular}

a $\mathrm{p}<0.05$

b $\mathrm{p}<0.01$

c $\mathrm{p}<0.001$

For the analysis of data, the subjects were grouped on the basis of ascending $2 \mathrm{~h}$ plasma glucose levels. The $2 \mathrm{~h}$ plasma glucose levels ranged between 55 and $665 \mathrm{mg} / 100 \mathrm{ml}$.

Statistical analyses were performed using the Statistical Package for Social Sciences [12].

The distribution of both arithmetic glucose and insulin values showed considerable skewing. As logarithmic transformation normalized the distribution, these values were used whenever statistical testing requiring the assumption of normally distributed data with common variances was employed.

\section{Results}

The relationships between fasting glucose and insulin and $2 \mathrm{~h}$ glucose and insulin are shown in Figure 1. No statistically significant correlations were found between corresponding plasma glucose and insulin levels.

Table 1 and Figure 2 show the patterns of changes of fasting and $2 \mathrm{~h}$ insulin values in groups (numbered 1 to 6 ) with increasing degrees of glucose intolerance.

The mean fasting insulin levels ranged between 16 and $32 \mu \mathrm{U} / \mathrm{ml}$. Analysis of variance showed there were no statistically significant differences between the groups.

The $2 h$ insulin response was highest in the group with $2 \mathrm{~h}$ plasma glucose $140-199 \mathrm{mg} / 100 \mathrm{ml}$ (group 3). In groups with $2 \mathrm{~h}$ plasma glucose exceeding $200 \mathrm{mg} / 100 \mathrm{ml}$ (groups 4-6), there was a progressive fall in $2 \mathrm{~h}$ insulin levels. The $2 \mathrm{~h}$ insulin level in the $2 \mathrm{~h}$ plasma glucose group $\geqslant 400 \mathrm{mg} / 100 \mathrm{ml}$ (group 6) with severe diabetes was the lowest and was significantly less than group $1 \quad(p<0.05$, Table 1). Also $2 \mathrm{~h}$ insulin levels of groups 2 to 4 were significantly greater than group 1 (Table 1 ).

Table 1 also shows the mean body mass index of 

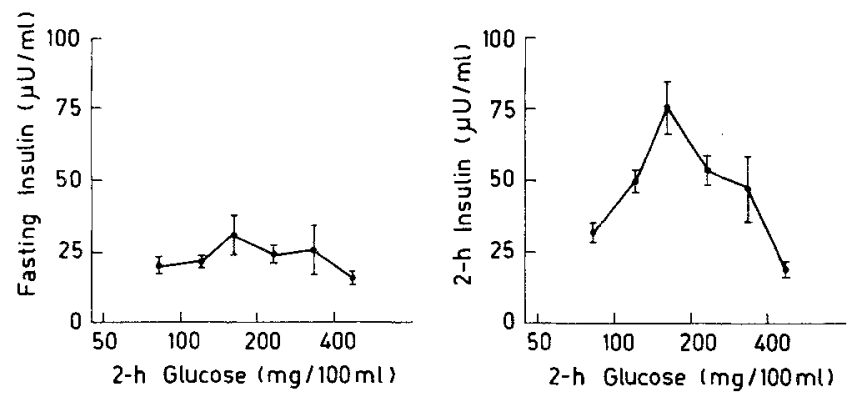

Fig. 2. Mean plasma insulin concentration ( \pm SEM) at fasting and 2 -h according to mean log plasma glucose concentration of the $2-\mathrm{h}$ glucose groups
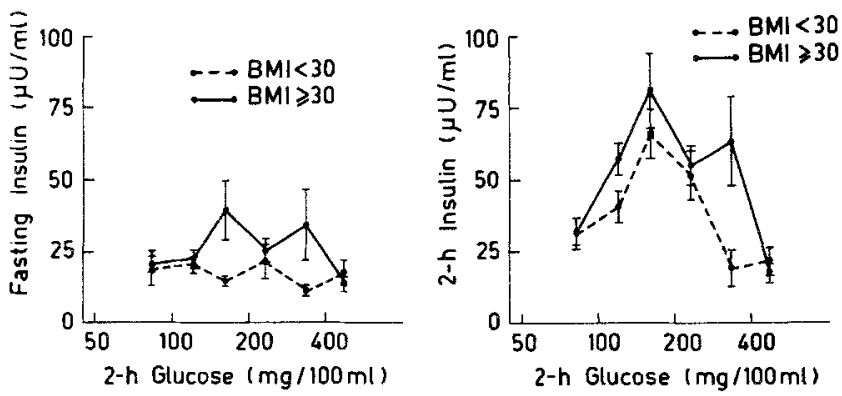

Fig. 4. Mean fasting and 2-h plasma insulin concentration ( \pm $\mathrm{SEM}$ ) according to $\log 2-\mathrm{h}$ plasma glucose concentration in nonobese subjects, i. e. body mass index $(\mathrm{BMI})<30$, and obese subjects, i. e. body mass index $\geqslant 30$
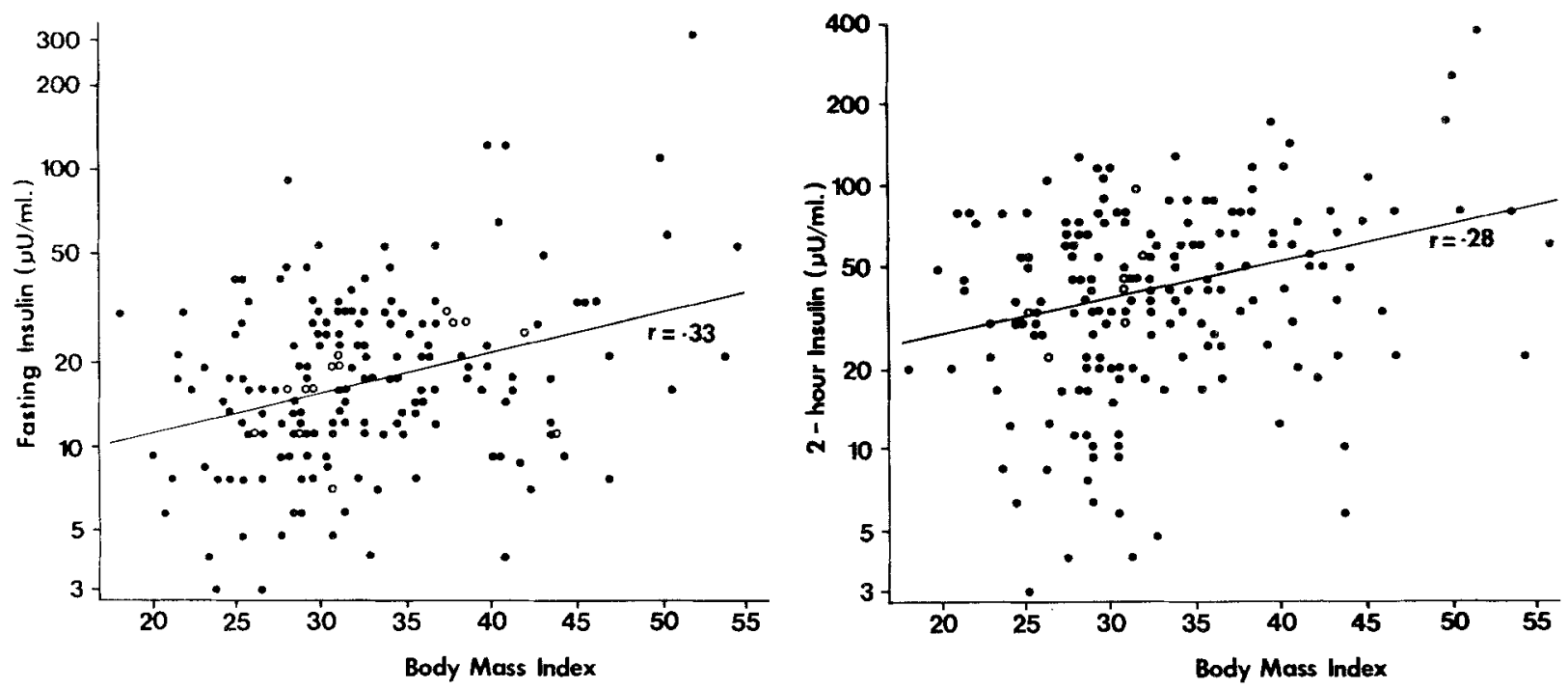

Fig. 3. Relationship between log fasting plasma insulin concentration and body mass index ( $\mathrm{n}=188, r=0.33, \mathrm{p}<0.001)$ and $\log 2$ hour insulin concentration and body mass index $(\mathrm{n}=188, \mathrm{r}=0.28, \mathrm{p}<0.001)$

each of the groups; there was no significant difference in the degree of obesity between the groups to account for any differences in the basal or incremental insulin responses between the groups.

One of the factors which may influence the pattern of insulin response to oral glucose is obesity. Figure 3 shows the analyses of the relationship of body mass index and logarithmic insulin values at the two sampling times. Obesity, as measured by body mass index, correlated significantly with both the fasting and $2 \mathrm{~h}$ insulin levels (both $\mathrm{p}<0.001$ ).

Figure 4 demonstrates the effect of obesity over the whole range of $2 \mathrm{~h}$ plasma glucose levels. Within each group, as determined by $2 \mathrm{~h}$ plasma glucose levels, the subjects with body mass index $\geqslant 30$ had higher mean insulin levels than those in $<30$ group, apart from group 6 ( $2 \mathrm{~h}$ plasma glucose $\geqslant 400 \mathrm{mg}$ / $100 \mathrm{ml}$ ). Only in group 2 did the obese (body mass index $\geqslant 30$ ) and non-obese (body mass index $<30$ ) subjects matched for $2 \mathrm{~h}$ plasma glucose and $2 \mathrm{~h}$ insulin levels show significantly different values $(\mathrm{p}<0.05)$.

\section{Discussion}

The patterns of insulin response in urbanized Micronesians with a wide spectrum of glucose intolerance are similar to those reported in the Pima Indians [4]. Despite fasting plasma glucose levels of over $473 \mathrm{mg} / 100 \mathrm{ml}$, fasting insulin levels were not significantly different. Like the Pima study [4], as the fasting levels were relatively constant over the entire range of glucose tolerance so the patterns of change in insulin levels at $2 \mathrm{~h}$ during the glucose tolerance test were essentially similar, whether absolute insulin 
values or the incremental rise in insulin above fasting concentration were considered.

Because of the nature of the survey, we were unable to obtain insulin levels at time intervals between fasting and $2 \mathrm{~h}$. This would have been desirable to indicate whether delayed insulin release was a characteristic of any or all of the groups of diabetic subjects. However, the $2 \mathrm{~h}$ insulin levels reported here show a similar pattern to the Pima data [4]. In view of the similarity of these populations in other respects [5], it seems likely that the patterns of response during the glucose tolerance test would also be similar.

Numerous reports have shown that obesity is associated with increased insulin levels over the entire range of glucose tolerance [3]. While we have shown a significant correlation between fasting and $2 \mathrm{~h}$ insulin levels and obesity in this population, there was no difference in degree of obesity between the six groups with differing degrees of glucose tolerance. Therefore, while the degree of obesity may have had some effect on the absolute values of plasma insulin, the differing patterns of response by the groups bore no relationship to obesity.

Savage et al. [4] have summarized the literature relating to the various patterns of insulin response to glucose reported by other workers. Our data support their conclusion that much of the controversy concerning the patterns of insulin response in diabetes has arisen from equating groups of subjects with various degrees of abnormality in glucose tolerance. It is quite clear that a wide range of responses - from hypoinsulinaemia to hyperinsulinaemia - will be seen and the response is very dependent on the degree of glucose intolerance of the subjects studied.

The Pima and Nauruan data may be of more than passing importance. The bimodal phenomenon has been demonstrated in glucose tolerance distributions in both of these populations $[13,14]$. The proportion of subjects in the second or "diabetic" component increases with age [13]. This increase presumably results from subjects initially in the first component developing glucose intolerance (and diabetes) as they aged. The actual mechanism has not been established but the insulin data reported here and elsewhere [4] may be relevant to the problem.

It is of interest that the $2 \mathrm{~h}$ plasma glucose level at which the insulin levels begin to decline (i. e. $280 \mathrm{mg} /$ $100 \mathrm{ml}$ ) closely approximates the glucose level at the point of separation of the two populations in the bimodal distribution of $2 \mathrm{~h}$ plasma glucose levels in both Pima Indians [13] and Nauru islanders [14]. It could be argued that the bimodal distribution of $2 \mathrm{~h}$ plasma glucose levels indicates two different populations, a normal and a diabetic group.
Another postulation, however, would be consistent with the blood glucose and insulin data, i. e. that there is only a single population containing a proportion of subjects with varying degrees of hyperglycaemia. Compensatory hyperinsulinism may for some time prevent severe hyperglycaemia. However, once a critical level of hyperglycaemia is reached (i. e. $2 \mathrm{~h}$ plasma glucose of approximately $280 \mathrm{mg} / 100 \mathrm{ml}$ ) beta cell function begins to fail and there is more rapid progression of hyperglycaemia. Thus, individuals might for some time remain in the 'compensated' phase of moderate hyperglycaemia and then move rapidly to a 'decompensated' phase of severe hyperglycaemia with a 'falling' insulin response. The decompensation may occur so rapidly, in fact, that a cross-sectional study of such population at any one time might show a bimodal distribution of blood glucose levels even though there is a continuing spectrum of glucose intolerance.

At present, this postulation must remain speculative and can only be proven by serial prospective studies of glucose tolerance and insulin responses in subjects in the normal component. Studies such as these are now being undertaken.

Acknowledgements. This work has been supported in part by a grant from the National Health and Medical Research Council of Australia. The authors wish to thank the Nauru Government for their support and for allowing the project to proceed, and Miss R. Swan for help in preparing the manuscript.

\section{References}

1. Reaven, G., Miller, R.: Study of the relationship between glucose and insulin responses to an oral glucose load in man. Diabetes 17, 560-569 (1968)

2. Yalow, R.S., Berson, S. A.: Immunoassay of endogenous plasma insulin in man. J. Clin. Invest. 39, 1157-1175 (1960)

3. Kipnis, D. M.: Insulin secretion in normal and diabetic individuals. Adv. Intern. Med. 16, 103-134 (1970)

4. Savage, P. J., Dippe, S. E., Bennett, P. H., Gorden, P., Roth, J., Rushforth, N. B., Miller, M.: Hyperinsulinaemia and Hypoinsulinaemia. Insulin responses to oral carbohydrate over a wide spectrum of glucose tolerance. Diabetes $\mathbf{2 4}, 362-368$ (1975)

5. Zimmet, P., Taft, P., Guinea, A., Guthrie, W., Thoma, K.: The high prevalence of diabetes mellitus on a Central Pacific island. Diabetologia 13, 111-115 (1977)

6. Bennett, P. H., Burch, T. A., Miller, M.: Diabetes mellitus in American (Pima) Indians. Lancet 1971 II, 125-128

7. Ringrose, $H$., Zimmet, P.: Nutrient intakes in an urbanized Micronesian population with a high diabetes prevalence. Am. J. Clin. Nutr. (in Press) (1978)

8. Freychet, P., Roth, J., Nelville, D. M.: Monoiodoinsulin: demonstration of its biological activity and binding to fat cells and liver membranes. Biochem. Biophys. Res. Commun. 43, 400-408 (1971)

9. Herbert, V., Lau, K. S., Gottlieb, C. W., Bleicher, S. J.: Coated charcoal immunoassay of insulin. J. Clin. Endocrinol. Metab. 25, 1375-1384 (1965) 
10. Evans, J. G., Prior, I. A. M.: Indices of obesity derived from height and weight in two Polynesian populations. Br. J. Prev. Soc. Med. 23, 56-59 (1969)

11. Keys, A., Fidanza, F., Karvonen, M. J., Kimura, N., Taylor, H.: Indices of relative weight and obesity. J. Chronic Dis. 25, 329-343 (1972)

12. Nie, N. H., Hull, C. H., Jenkins, J., Steinbrenner, K., Bent, D. H.: Statistical Package for the Social Sciences. 2nd edition, New York: McGraw-Hill, Inc. 1975

13. Rushforth, N. B., Bennett, P. H., Steinberg, A. G., Burch, T. A., Miller, M.: Diabetes in the Pima Indians: Evidence of bimodality in glucose tolerance distributions. Diabetes 20, $756-765$ (1971)
14. Zimmet, P., Whitehouse, S.: Bimodality in glucose tolerance - the phenomenon and its possible significance. Diabetologia 13, 441 (1977)

Received: December 9, 1977,

and in revised form: March 7, 1978

Dr. P. Zimmet

Department of Metabolic Medicine and Epidemiology

Southern Memorial Hospital

Caulfield 3162

Australia 